\title{
EDITORIAL
}

\section{The Well-Tempered Clinic: The Clinical and Educational Importance of Cardiovascular Surgical Clinics (With a nod to Johann Sebastian Bach)}

\author{
Curt Tribble, MD \\ ${ }^{1}$ Division of Cardiac Surgery, University of Virginia, Charlottesville, VA, USA
}

\section{INTRODUCTION}

A common assertion regarding the trajectory of surgeons from training to independent practice is that the first five years after completing training encompass the steepest learning curve of a young surgeon's career. That assertion is often made in the context of beginning to perform operations independently. However, it is likely that an under-recognized but equally steep learning curve will occur as newly minted surgeons begin to run their own clinics. In fact, it is likely that there is no aspect of surgical training with a greater discrepancy between the educational value for and the interest by surgical trainees than preoperative, postoperative, and followup clinics for surgical patients.

One reason for the 'steepness' of this particular learning curve is that residents almost universally avoid going to clinics as much as they can, typically failing to recognize how much there is to be learned in the clinics of their mentors, not only about pertinent clinical scenarios but also about how to manage the work flow, talk to patients and their families, make difficult decisions about offering, or declining to offer, a surgical intervention, and make recommendations for 'health maintenance.' As one of my former residents said, early in his career, "I realize now that I had little to no idea which patients were not being offered an operation in your clinics, and, even more importantly, what those conversations entailed."

Therefore, recognizing the need to provide additional guidance in this realm for our protégés, I will offer some suggestions about running an efficient, effective, and satisfying clinic for cardiovascular patients. These reflections are based on four decades of observations made while caring for patients with cardiac, thoracic, and vascular conditions, as well as on decades of involvement in heart and lung transplant programs.

Correspondence: Curt Tribble, MD, Professor of Cardiothoracic Surgery, University of Virginia Health System, Division of Cardiac Surgery, Box 800679, Charlottesville, VA 22908; 434-243-9250 (e-mail: ctribble@virginia.edu).

\section{PREPARING FOR CLINIC}

By failing to prepare, you are preparing to fail. - Benjamin Franklin

Proper preparation for clinic is essential, to optimize both efficiency and effectiveness. One important, but often overlooked, aspect of preparing for clinic is the need to choose the proper template for the schedule. A template that I have found to work well is to schedule one new or fairly complex patient per hour and two or three follow-up patients in that hour as well. This alignment allows appropriate time and attention for the more complex patients while decreasing the chance of falling behind in your schedule. Another scheduling strategy I adopted was to schedule a break in the middle of the clinic day. While these breaks rarely ended up being actual lunch or coffee breaks for me, they did result on our being on time at least twice each clinic day.

I found it optimal to have a consistent person or team that would communicate with the patients ahead of time and afterwards, as needed. The patients and their families appreciated immensely having a friendly person they know is connected with the practitioner with whom they could communicate about scheduling and other details of getting to the clinic, as well as many other issues.

Another aspect of preparing for a clinic session is to focus, ahead of time as much as feasible, on the new or complex patients you expect to see in that clinic. This preparation should include reviewing the available notes and letters, the studies and images, and any other communications about the patient that you have received. Your efficiency on the day of the clinic can be further improved by printing out a hard copy of some sort of summary of this 'pre-clinic' information which can facilitate adding hand written notes to that summary, rather than trying to enter that information directly, in the moment, into the electronic medical record (EMR). The necessary balance of efficiency and effectiveness can be further enhanced by focusing on listening to and talking with the patient and the family, while someone else, such as a nurse, advanced practitioner, or a scribe, takes notes. When these notes are added to a previously organized document and subsequently edited, the resulting document can then be copied into your EMR. This process can be both efficient and effective, optimizing the preparation, the interactions in the clinic, and the formal record eventually placed in the EMR. 
Some patients can also help with your clinic preparation. I have had patients who kept meticulous, well-organized notes about their health care, creating lists of their problems, medications, allergies, past medical history, contact information, other physicians who they see regularly, and advance directives. Most patients who are this well-organized will be happy to provide a copy of this information to you, if asked. Therefore, it will never hurt to ask them if they have records of this sort, especially if they are new to your practice. Furthermore, it is also worth considering having the patients and their families fill out questionnaires upon arriving at your office, which can further facilitate the process of getting information about them logged into your system.

\section{RUNNING AN EFFICIENT CLINIC}

To achieve great things, two things are needed; a plan and not quite enough time.-Leonard Bernstein

In addition to thorough preparation and creating an optimal schedule, one must also have a strategy for running a busy clinic efficiently. In the vernacular of surgical practice, the term 'single warrior combat' is often used. Most often this concept refers to carrying out surgical procedures. However, this concept also applies to running a surgical clinic, recognizing that the patients expect to see and have meaningful conversations with their surgeon and that it is only this clinician who can make the ultimate decisions, with the patient, about what the next logical steps of care will be.

However, there is value, both from a logistical standpoint and from an educational standpoint, in having an array of other clinical 'allies' participate in seeing the patients. Over the years of my practice, I came to appreciate the validity of an old adage, which is that the patients have a sense that they should have about 20 minutes of direct contact with the clinic team during an office visit. Some of that time can be usefully accrued by having others see the patients first, a process we came to describe as 'softening them up.' Obviously, there are 'housekeeping chores' that others can perform, such as getting the patient on an exam table, removing dressings when appropriate, and instructing the patient on the necessary state of attire for the issue of the day. Of course, these initial parts of the encounter will be more efficient and helpful if the assistants are knowledgeable about what needs to be done to prepare the patient for your time with them and what can be appropriately discussed with the patients during this initial part of the clinic encounter.

However, no matter how well you and your team prepare, you will inevitably get behind in clinic from time to time. One of my favorite referring physicians, who was said to be the busiest primary care physician in the state, told me about how he handled this situation when he walked into the room of a patient who had been waiting on him longer than expected. He claimed that he would say "I know you've been waiting on me for a while. Today's visit is going to be free. Now, tell me how I can be of help to you." He said that this quip always changed the tenor of the subsequent conversation. In general, when these inevitable delays do occur, you should apologize to the patient and the patient's family and then proceed to give them your undivided attention.

\section{I write to find out what I think. Stephen King}

Since patients seen in a cardiovascular surgery clinic are virtually always referred by another practitioner, communicating effectively with those who referred you the patient is crucial, not only for good patient care but also for building and maintaining excellent relationships with these referring physicians. One way to enhance this goal is to dictate letters directly to those practitioners, which I have done throughout my career. I found it most efficient to dictate such notes immediately after seeing each patient in my clinic, rather than doing these dictations at a later time. While some have suggested that there may even be advantages to dictating such notes in the presence of the patient and the patient's family, I have not used that approach myself, at least partly recognizing the need to optimize patient flow in the clinic. When these letters are transcribed, preferably within a day or so, you should carefully review and edit them before they are sent out to the referring physicians and included in the EMR. I found that I would almost always have some additional reflections to add to these notes, when reviewing them later. You will definitely want to explain your decision making process and to ask for any additional input that the referring physician may have. Over my many decades of practice, the feedback I have received from my referring practitioners about these letters has been overwhelmingly positive.

\section{BEING PRESENT IN YOUR CLINIC}

I've learned that people will forget what you said, people will forget what you did, but people will never forget how you made them feel. Maya Angelou

Your patients will assess you in your encounters with them, as they will be deciding whether to trust you with their care, especially if their visit is their first with you for a given condition. And, as the old saying goes, you never get a second chance to make a good first impression. One of the issues that surgeons heading to clinic need to consider is what to wear when in clinic. When I was a medical student and asked what we should wear on the wards and in clinics, a common answer was "dress to inspire confidence." While many physicians feel that it is perfectly acceptable to wear scrub clothes in the clinic, at least some of our patients are put off by that practice. I suppose you cannot blame them for, at least occasionally, wondering where you might have been in those scrubs. Their concerns will, of course, be even greater if the scrubs are not clean. I have always felt that I owed it to my patients to show up, at least when I could, dressed professionally, wearing a white coat over what is generally described as 'business attire.' Another strategy that one must employ, if at all possible, is to sit down when you are talking to patients. In fact, it is best if you can sit somewhere so that you can avoid looking down on the patient. [Tribble, Grandmother Rules] 


\section{Every illness is not a set of pathologies but a personal story. Anne Fadiman}

I once met a woman and her family who were coming to me for a second opinion about a peripheral vascular issue. I learned that she had undergone an uncomplicated carotid endarterectomy by another surgeon, who had recommended that she have a second vascular operation after she recovered from the endarterectomy. I asked why she had traveled a fairly long way to see me to discuss this second operation rather than returning to the first surgeon. I'll never forget her answer, which was "I would never go back to that surgeon, because he is one of Satan's Disciples." It was all I could do not to laugh out loud, having never heard a patient describe a doctor that way. Of course, the patient was unhappy with the way that physician had spoken to and treated her, and she was determined to find a surgeon who would treat her with what she viewed as dignity and respect. I suppose she decided that I was not one of "Satan's Disciples," as she asked me to do her bypass operation. Over the ensuing 20 years or so, I operated on her several more times, performed both cardiac and vascular operations on her husband, and became almost a part of their family. In fact, that couple's children still send me notes and pictures of their families.

While I am not sure that one can dramatically change one's speaking style, it is worth remembering that studies have shown that one's tone of voice is of the utmost importance in establishing a good, trusting relationship with patients. [Levinson, Surgery] On balance, it is hard to argue with the old adage that benefits accrue when the physician, the patient, and the family like each other.

Another issue to try to avoid is looking at or, even worse, working on a computer while talking to a patient. Avoiding interacting with a computer while in a clinic room is challenging these days, of course. I like the advice I heard from a primary care doctor who is an acquaintance of mine, who said that if you are entering or looking up factual data, you will probably be forgiven by the patient for looking at a computer screen. However, if your patient is telling you something important, and especially something with emotional content, you simply must give them your undivided attention.

In an initial visit, you must take the time to get to know your patient, at least to some degree. One easy thing to ask them about is where they live. The longer you work in a given area, the more you will know something about the places that your patients come from. I have always tried to learn about the areas that most of my patients lived. I learned that it is a source of comfort to people when you can accurately say that you know something about where they were from. One way or another, you should also learn something about every patient, which can include things such as what they enjoy doing. And, though you may remember what they have told you, it cannot hurt to keep notes about these activities in your records (perhaps under 'social history') to jog your memory later. You should strive to ask the patient about these issues at every visit. [Tribble, Gimme 3 Steps]
I ain't lookin' for praise or pity. I ain't comin' 'round searchin' for a crutch.

I just want someone to talk to. And a little of that human touch. Bruce Springsteen, Human Touch

You must always examine your patient, even if you are conducting only a 'focused physical exam.' As the old adage goes, "you must examine the part that hurts." For instance, I might already have all kinds of information about a patient's valve abnormality, but I will always take out my own stethoscope and listen to the patient's heart myself.

When you are discussing a proposed operation, you must take whatever time is necessary to listen to and answer every question asked by the patient and family. I have made it a practice to say "now, that is a great question" prior to answering, regardless of how uninformed or trivial the question might have seemed to me. After all, not many of our patients will be all that knowledgeable about the treatment or the operations we are proposing to them.

Like it or not, there is a little witchdoctor operating in all physicians. Use that skill wisely and only for the benefit of your patients. Clifton Meador

I have found it quite useful, when feasible, to show patients any of their imaging studies that are pertinent to the issue at hand. Of course, most of the time they will not truly understand these images, but it is likely that they will have at least some appreciation of what they are being shown. A humorous example of this practice was when I learned that the father of a friend of mine was quite concerned that the coronary artery bypass grafts that we had done for him a year earlier were failing. As an aside, this patient's concerns seemed to have arisen from some inaccurate 'chatter' that he had overheard during the hospitalization prior to his operation. Eventually, I saw no way to convince him otherwise without having a cardiac catheterization done. The grafts were all beautiful (thank goodness). I showed him the cath films, and, with each injection, I noted how each graft looked good, with "the blood rushing through each of the bypass grafts." The patient left a happy man. And, his son told me years later that his father, obviously a bit of a hypochondriac, never worried about his heart again.

There are many additional issues to be considered if a clinic visit includes obtaining consent for an operation. These issues have been addressed thoroughly in an earlier essay, so I will not review them again here. [Tribble. First, We Do Harm]

\section{WHAT, THEN, SHALL I DO BETWEEN OFFICE VISITS? (WITH A NOD TO BERNIE SIEGAL, MD)}

The good physician treats the disease; the great physician treats the patient who has the disease. - Sir William Osler

There are many reasons that we should help our patients take at least some control of their own health. Those reasons include the facts that that we, of course, want them to be as healthy as possible and that we are often interacting with them 
at the time of a health scare or even a health crisis which can create 'teachable moments.' Furthermore, our patients will generally believe that we are knowledgeable about health related issues, particularly those that pertain to patients with cardiovascular conditions. And, focusing on health and on what is right about the patient is more engaging and effective than focusing entirely on what is wrong with them. Finally, it is worth noting the old tenet that people generally will need to hear or read a suggestion approximately seven times before they will act on it, a concept that should prompt us all to reiterate salient advice for our patients as often as is feasible. There are three main health related issues that we should address with our patients who have cardiovascular conditions, which are: smoking, diet, and exercise.

\section{If people quit smoking, I'd be out of a job.}

A cardiothoracic surgeon friend of mine used to sign his emails with this quip about smoking. While that assertion is unlikely to be true in the short term, there is no doubt that smoking has probably contributed to many of the conditions that we, as cardiovascular and thoracic surgeons, treat. Though some might think that counseling patients on smoking cessation is futile, I do not believe that to be the case. First of all, the smokers are well aware that smoking has almost certainly contributed to most of the medical conditions for which they are seeing us. Second, if or when they have an operation they will have to abstain from smoking at least for a time, which is an opportunity to discuss getting a head start on 'kicking the habit.' Furthermore, it has been shown that even a few minutes of counseling can increase the likelihood of a smoker's quitting the habit. [Cheung. JAMA Internal Medicine, 12-19] Thus, it is incumbent on us, the patients' physicians, to take advantage of this 'teachable moment.'

\section{What's missing in the toolkit of most doctors is the ability to guide an individual, whether they are healthy or sick, on how they can use food as a way to resist disease.}

William $\mathrm{Li}$

Patients are generally also aware that their diets have likely contributed to their medical conditions. It seems only reasonable that we stand ready to answer their questions about their diets. My own approach is start by saying something like "you don't have to eat sawdust and dirt." I then follow that quip by telling them that they should eat as many plants as possible, especially fresh fruits and vegetables. I was reminded by an interview with a former student of mine, Dr. Travis Stork, now a fairly well-known 'TV doctor,' that I would commonly say to my protégés that I had found myself feeling sheepish about insisting that my patients eat foods that I myself did not eat regularly, like fish. [Sole-Smith, 2013] When I recognized that I did not want to be hypocritical about the dietary advice I was giving, I took it upon myself to figure out which 'healthy' foods I might like to eat and how best to prepare them. Over time, I did find that I was eating more and more fish and less red meat, adding, at least in my own mind, some credibility to the advice I was giving my patients.

\section{Start off slow, then taper off. \\ Walt Stack}

Most of the patients that thoracic and cardiovascular surgeons see in their offices will be middle aged or older adults, many of whom are not as active as they should be. Therefore, any advice on exercise offered to these patients must be tailored to people of this age. And, it has seemed to me to be appropriate to give them some encouragement, along with advice, about getting exercise of some kind. Many of our patients will have limited knowledge about how to regain or maintain some semblance of fitness and, importantly, will also often be of limited financial means. Thus, simple, realistic, and affordable suggestions on fitness will be those most likely to be adopted by our patients.

One general strategy that I have found to be effective for patients is one that I myself adopted many decades ago, which is to keep an exercise (or health) log. Many will derive some inspiration from looking at a record of what they have done. One of my former students, Dr. Tom Masterson, even developed and published a series of logs or diaries that were designed for specific conditions, such as diabetes or arthritis. [Masterson, International Publishing] You can invite your patients to bring records of this sort with them to their clinic visits, which will enhance the impact of these logs.

\section{Start where you are. Use what you have. Do what you can. Arthur Ashe}

With regard to general muscular fitness, you can make several suggestions that virtually any patient, no matter how decrepit they are, will be able to do. One is to walk up stairs, counting the steps or flights to track their daily 'accomplishments.' Another is to have them round up two empty one gallon milk jugs which they can move around in various ways to improve muscle tone and flexibility. For instance, they can lean over and raise the jugs parallel to the floor, a move a fitness instructor might call a 'bent over fly.' Or they can push their jugs up over their heads, which is described as a 'military press.' Once they get used to these movements, they can add water to the jugs to increase the resistance. It is worth noting that a gallon jug filled with water weighs eight pounds, which is surprisingly heavier than one might think.

Of course, the best all-round fitness activity for older patients with cardiovascular issues is walking. However, I found, over many years of counseling patients, that access to safe, reasonable places to walk is more limited than one might imagine. Of course, some patients are fortunate enough to live where access to safe places to walk is available, such as shopping malls or the tracks at local schools. However, it seems that many localities, including my own, have begun restricting access to school grounds outside of regular school hours, and malls all over the country seem to closing in recent years. As I became aware of these trends and tried to think of ways to facilitate access to places to exercise for my patients, who are generally older and who are often 'financially challenged,' I met with the owner of one of our local health clubs and made a 'modest proposal.' I pointed out that many older 
persons would find both the cost and the environment of most health clubs to be daunting. I proposed creating a program in which a physician in our area could write an 'exercise prescription' that the patient could bring to the club, which would allow them to exercise there for a dollar a day for a period of time, with no upfront membership fees. The owner agreed to try this idea, and the plan was eventually 'rolled out' to most physicians in the region. Many patients and physicians have taken advantage of this program, and, as expected, many eventually joined the club and became regular members. This program is still going strong in our area, more than 20 years after its inception, and the owner of the club has received local recognition for 'promoting health in the community.' [The ACAC Physician Referred Exercise Program]

\section{CLINIC AS ANTIDOTE TO BURNOUT}

Although physician-patient relationships may face more challenges now than in the past, they are still at the heart of the reason why physicians choose their professions. And, many patients consider these relationships equally as important.-Debra A. Shute

Almost all physicians choose to enter medicine altruistically wanting to help patients maintain or regain health. Those who choose an interventional discipline in which to practice generally come to realize that, in addition to helping people in general, they also found that they got a visceral satisfaction from doing things, such as performing procedures. However, most surgeons can get an additional, and different, kind of satisfaction from helping their patients prepare for their procedures and from seeing their patients do well afterwards. It is vital that we understand the importance of our personal relationships with our patients and the value to them of encouraging healthy habits. In fact, I believe that these relationships can be an antidote to burnout.

Perhaps 35 years apart, my father and I might have done the very same colectomy, but if I am doing something important, the sense is far more abstract for me than it was for him. We can fix the hours all we want, but unless we find a way to revive the relationship between resident and patient, and thus the dedication and purpose that fuel imagination, then the quality will not be what it was, let alone what we want it to be.

Atul Gawande

Burnout in clinicians of all types is a frequent topic of discussion and examination in both the professional literature and the lay press. One of the antidotes to burnout that many clinicians believe to be pertinent is having good, fulfilling relationships with patients. These relationships between surgeons and their patients, while different from the relationships of primary care physicians with their patients, are equally important.

We're in such a burry most of the time we never get much chance to talk. The result is a kind of endless day-to-day shallowness, a monotony that leaves a person wondering years later where all the time went and sorry that it's all gone.

Robert Pirsig
While it is rewarding to meet patients in an hour of need, it is also fulfilling to see them in a more longitudinal manner. I had the great privilege, for many years, of practicing both cardiac surgery and vascular surgery. While many of my cardiac patients would not need to continue to follow up with me for the long term, my vascular patients, more often than not, would do so. While I have written before about strategies for connecting with patients around the time of discussing and then doing operations [Tribble, Gimme Three Steps], I developed a different strategy for having a more longitudinal relationship with my vascular patients. In fact, I sensed that my vascular patients came to regard me more as one of their primary physicians than as 'just their surgeon,' and I enjoyed being involved in their care in this way. We can all develop close relationships with the patients that we see over time.

For sixty years I still have not lost my sense of wonder, amazed at how extraordinary the ordinary person is if you know them well and I try to know them well and it keeps me alive, wanting to know more Gay Talese, Author

Occasionally, you will be surprised when one of your patients brings you something to show their appreciation for your care. While I have had this happen many times, one of the most memorable gifts that a patient, for whom I had done an emergency carotid endarterectomy for an evolving stroke, gave me was a black bear skin. Many years and multiple moves later that bear skin rug remains a family heirloom.

Meaningfulness in this profession comes from one-on-one interactions with patients. The moment you feel like you're just another widget, it just takes the soul out of many physicians' lives. Abraham Verghese

\section{CONCLUSIONS}

Fust as systemic processes of the body, such as hypertension, diabetes mellitus, and obesity can adversely affect the heart and cardiovascular bealth, so can dysphoric and negative psychological states and processes of the mind.-Glenn Levin (Circulation, 2019)

The state of mind of our patients influences their health and their capacity to deal with the adversity of their medical conditions and the treatment of those conditions. It is our job, and our privilege, to try to optimize the medical care of and the surgical interventions for our patients. However, much of the care of our patients will occur outside of an operating room. Thus, it is incumbent on us, their surgeons, to be attentive to all aspects of our patients' lives. It will be good for them, and it will be good for us as well.

\section{ACKNOWLEDGMENTS}

I would like to recognize some of the many nurses, assistants, and advanced practitioners who have helped me, over many decades, create the kind of environment that we thought was optimal for the care of our patients. Some of these valuable 
allies are: Nancy Jensen, Garnette Meadows, Tarie Dean, Chris Wells, Ashley Shivers, and Gretchen Shull. I would also like to acknowledge some of my mentors who taught me valuable lessons about running an efficient and effective clinic, including Linn Tompkins, Clifton Meador, David Tribble, George Minor, and Morton Wilhelm. Finally, I would like to acknowledge the helpful suggestions of Mark van Yahres, a local keyboardist and expert on Johann Sebastian Bach.

\section{APPENDIX}

The title of this essay, 'The Well-Tempered Clinic,' is a reference to a collection of preludes and fugues entitled 'The Well-Tempered Clavier,' which was written by Johann Sebastian Bach and published in the early 1700's. The term 'welltempered' refers to a tuning system for keyboard instruments, so 'well-tempered' could be considered to mean 'well-tuned.' The term 'clavier' was used to refer to any keyboard instrument of that era, including the harpsichord, the clavichord, and the organ. The piano had only been recently invented and was unknown to Bach and his German audiences of the time. Bach's collection was said to have been created to allow practice and exposition on the keyboard instruments of the day for all reasonably competent players. [Schwarm] In summary, I have used the term, 'well-tempered' in this essay to refer to a 'well-tuned' clinic.

\section{REFERENCES}

Franklin B. https://www.brainyquote.com/quotes/benjamin_franklin_138217 (Accessed 2-10-20).

Bernstein, L. https://www.classicfm.com/composers/bernstein-1/guides/ leonard-bernstein-quotes/great-things/ (Accessed 2-10-20.

King S. https://www.goodreads.com/quotes/134620-i-write-to-find-outwhat-i-think (Accessed 2-7-20).

Maya Angelou https://www.goalcast.com/2017/04/03/maya-angelouquotes-to-inspire-your-life/ (Accessed 1-21-20).

Tribble C. 2017. Grandmother Rules. Heart Surg Forum 20 (1): E002-6.

Fadiman, A. The Spirit Catches You and You Fall Down: A Hmong Child, Her American Doctors, and the Collision of Two Cultures. New York: Farrar, Strauss and Giroux, 1997.

Levinson, W. 2002. Surgeon's tone of voice: A clue to malpractice history. Surgery 132: 5-9.

Tribble C. 2016. Gimme 3 Steps. Heart Surg Forum 19 (1): 1-2.

Springsteen, B. 1992. Human Touch. www.azlyrics.com. (Accessed 2-7-20).

Meador, C. A Little Book of Doctors' Rules III. 2018. https://www.cliftonkmeador.com/little-book-of-doctors-rules-3. (Accessed 1-21-20)

Tribble, C, Julliard W. 2019. First, We Do Harm. Heart Surg Forum 22 (5): 423-8.

Siegel, B. How to Live Between Office Visits: A Guide to Life, Love and Health. 1993. HarperCollins Publishers, Inc. New York, NY.
Osler W. https://www.brainyquote.com/quotes/william_osler_386616 (Accessed 2-7-20).

Cheung W, Ho K, Wang M. 2019. Effectiveness of a Brief Self-determination Theory-Based Smoking Cessation Intervention for Smokers at Emergency Departments in Hong Kong, A Randomized Clinical Trial. JAMA Intern Med. doi:10.1001/jamainternmed.2019. Published online December 2, 2019

William Li. 2019. Eat to Beat Disease: The New Science of How Your Body Can Heal Itself. Grand Central Publishing, Hachette Book Group.

Sole-Smith V. 2013. 6 Lifesaving Lessons from The ER, Courtesy of The Doctors' Travis Stork, MD. https://www.prevention.com/life/ g20495666/lifesaving-lessons-from-travis-stork/?slide=3 (accessed 1-31-20).

Walt Stack. https://en.wikipedia.org/wiki/Walt_Stack (Accessed 1-31-20.)

Masterson T, Dawn K, Levetan R, Ball J. 2004. Weekly Calendar: Diabetes Planner. International Medical Publishing, Inc. McLean, Virginia

Arthur Ashe. https://www.brainyquote.com/quotes/arthur_ashe_371527 (Accessed 2-4-20).

The ACAC Physician Referred Exercise Program. https://acac.com/ charlottesville/p-r-e-p/ (Accessed 2-7-20).

Shute D. 2019. Does a Real Physician-Patient Relationship Exist Anymore? https://www.medscape.com/viewarticle/922378 (accessed 1-30-20).

Gawande, A. 2000. Creating the Educated Surgeon in the 21st Century. Am J Surg 181: 551-6.

Pirsig R. Zen and the Art of Motorcycle Maintenance: An Inquiry into Values. 1974 \& 1999. HarperCollins Inc. New York, New York.

Gay Talese. https://www.cbsnews.com/news/gay-talese-sense-of-wonder/ (Accessed 2-7-20).

Verghese A. 2017. https://www.medscape.com/viewarticle/887249 (Accessed 2-7-20).

Levine, G. 2019. The Mind-Heart-Body Connection. Circulation 140: 1363-5.

Schwarm B. The Well-Tempered Clavier. Encyclopaedia Britannica. https://www.britannica.com/topic/The-Well-Tempered-ClavierBWV-846-893 (Accessed 2-7-20).

\section{ADDITIONAL REFERENCES}

A Good Physician - On Complacency and Communication. Michelle Kittleson NEJM 2019; 381: 1798-1799.

Gladwell M. 2019. Talking to Strangers. Little, Brown and Company. Hachette Book Group. New York, NY

Levinson J, Price B, Saini V. Death by a Thousand Clicks: Leading Boston Doctors Decry Electronic Medical Records. 2017. https:// www.wbur.org/commonhealth/2017/05/12/boston-electronic-medicalrecords (Accessed 1-21-20).

Tribble C. 2016. On Becoming a Doctor of Humane Letters. Heart Surg Forum. 19 (4): E150-2.

Harrington R, Rosenbaum L. A Cardiologist's Search for Medicine's Lost Heart. Medscape - February 10, 2020. https://www.medscape.com/ viewarticle/924328?nlid=133900_5461\&src=wnl_dne_200211_mscpedi t\&uac=138641MG\&impID=2274481\&faf=1\#vp_5 (Accessed 2-11-20). 